\title{
Diffusion-Controlled and Creep-Mitigated ASR Damage via Microplane Model. II: Material Degradation, Drying, and Verification
}

\author{
Saeed Rahimi-Aghdam ${ }^{1}$; Zdeněk P. Bažant, Hon.M.ASCE²; and Ferhun C. Caner, Aff.M.ASCE ${ }^{3}$
}

\begin{abstract}
The theory for the material and structural damage due to the alkali-silica reaction (ASR) in concrete is calibrated and validated by finite element fitting of the main test results from the literature. The fracture mechanics aspects, and particularly the localization limiter, are handled by the crack band model. It is shown that the theory can capture the following features quite well: (1) the effects of various loading conditions and stress states on the ASR-induced expansion and its direction; (2) degradation of the mechanical properties of concrete, particularly its tensile and compressive strength, and elastic modulus; (3) the effect of temperature on ASR-induced expansion; and (4) the effect of drying on the ASR, with or without simultaneous temperature effect. The finite element simulations use microplane model M7. The aging creep, embedded in M7, is found to mitigate the predicted ASR damage significantly. The crack band model is used to handle quasi-brittle fracture mechanics and serve as the localization limiter. The moisture diffusivity, both the global one for external drying and the local one for mortar near the aggregate, decreases by one to two orders of magnitude as the pore humidity drops. The fits of each experimenter's data use the same material parameters. Close fits are achieved and the model appears ready for predicting the ASR effects in large structures. DOI: 10.1061/(ASCE)EM.1943-7889.0001185. (c) 2016 American Society of Civil Engineers.
\end{abstract}

\section{Introduction}

After a review of previous studies, Part I of this paper presented the detailed development of a comprehensive mathematical model for predicting the effect of the alkali-silica reaction (ASR) on mass concrete. Part II refines the model and analyzes the effects of temperature, applied stress state, and external drying. Comparisons with experimental data from the literature are used to calibrate and verify the model.

\section{Localization Limiter and Heterogeneity}

The material modeling relies on a strain-softening damage constitutive law, for which microplane model M7 with embedded aging creep is adopted. To handle the strain-softening constitutive law objectively, a localization limiter must be used to avoid spurious mesh-size sensitivity. Here this purpose is served by the crack band model (Bažant and Oh 1983; Bažant and Planas 1997) in which the finite element size in a softening damage zone must be fixed and treated as a material property. Generally, if the element size is changed, the postpeak softening of the constitutive law must be adjusted so as to maintain a mesh-independent energy dissipation

${ }^{1}$ Graduate Research Assistant, Northwestern Univ., 2145 Sheridan Rd., CEE/A123, Evanston, IL 60208.

${ }^{2}$ McCormick Institute Professor and W.P. Murphy Professor, Dept. of Civil and Mechanical Engineering, and Materials Science, Northwestern Univ., 2145 Sheridan Rd., CEE/A123, Evanston, IL 60208 (corresponding author). E-mail: z-bazant@northwestern.edu

${ }^{3}$ Associate Professor, Energy Technologies (INTE/ETSEIB), Universitat Politécnica de Catalunya, Avinguda Diagonal No. 647, 08028 Barcelona, Spain.

Note. This manuscript was submitted on March 29, 2016; approved on August 25, 2016; published online on October 28, 2016. Discussion period open until March 28, 2017; separate discussions must be submitted for individual papers. This paper is part of the Journal of Engineering Mechanics, (C) ASCE, ISSN 0733-9399.
(Bažant and Oh 1983; Červenka et al. 2005). Such adjustment was not needed in this study, i.e., the element size was kept uniform, because the test specimens were small enough to avoid mesh coarsening. The finite elements were (even for axisymmetric situations) linear 6-node hex-element bricks of a size approximately equal to $15 \mathrm{~mm}$ for concrete and $2 \mathrm{~mm}$ for mortar. Because usually all of the aggregates are not reactive, it is considered that each large aggregate has a $50 \%$ probability to contain reactive silica. Because the size of each finite element is about equal to the maximum aggregate size, one half of finite elements are chosen, by a random number generator, to be reactive.

In this regard, heterogeneity is automatic in the lattice discrete particle model (LDPM) used by Allnagar et al. (2013) to fit part of the data fitted in this paper. In a continuum model such as this one, the heterogeneity must introduced because if the specimen were in a homogenous state, with uniform properties, all the finite elements would be expanding equally, creating no residual stresses and thus no damage. A randomization of strength was tried but omitted because the present randomization of reactive silica proved sufficient to fit the data.

\section{Effect of Various Loading Conditions on ASR-Induced Expansion}

Several experimental and numerical studies show that the type of applied stress state, particularly the ratio of various components of applied stress, has a large effect on the ASR-induced expansion in various directions (Ahmed et al. 1999; Alnaggar et al. 2013; Gravel et al. 2000; Larive et al. 1996; Multon and Toutlemonde 2006). However, the effect on the volume expansion of concrete is minimal. For instance, large compression in one direction simply transfers the expansion to another direction under smaller or zero compression.

The ability of the present ASR model to predict ASR-induced expansion and deterioration at different stress states can be checked by various published experimental data. First the accelerated 
laboratory tests of Multon and Toutlemonde (2006) are analyzed, considering the deformation and expansion due to ASR during the test period of 450 days to be comparable to those during 5-50 years in actual structures. In these tests, which involved concrete cylinders of $130 \mathrm{~mm}$ in diameter and $240 \mathrm{~mm}$ in height, with watercement ratio of 0.5 and cement content of $410 \mathrm{~kg} / \mathrm{m}^{3}$, the availability of alkali was ensured by dissolving potassium hydroxide in the mixing water to increase the $\mathrm{Na}_{2} \mathrm{O}_{\text {eq }}$ content to $1.25 \%$ of the mass of cement.

The alkalies present in portland cement are of different types, with different reactivity. Mostly they consist of potassium oxide, $\mathrm{K}_{2} \mathrm{O}$, and sodium oxide, $\mathrm{Na}_{2} \mathrm{O}$, the latter being more damaging. For the sake of simplicity, they are here characterized by one combined quantity, the equivalent sodium oxide content, labeled by subscript eq.

Because the moisture content has a strong effect on the ASR (Larive 1997; Olafsson 1986), all the specimens were sealed by a watertight jacket to obtain a statistically homogeneous state of moisture in each specimen. Minor defects in the jackets caused water losses $\leq 0.5 \%$ after 450 days for unconfined cases. For these cases, in addition to autogenous shrinkage, drying shrinkage is also considered. After 28 days of curing, nine different uniform stress states were applied to the cylindrical specimens. Each stress state involved three different cases: (1) free expansion, (2) expansion confined by a tubular $3 \mathrm{~mm}$-thick steel envelope, and (3) expansion confined by a tubular $5 \mathrm{~mm}$ steel envelope. The yield stress of steel was $206 \mathrm{MPa}$, and Young's modulus was $193 \mathrm{GPa}$. For each case three axial loading conditions were used: 0, 10, and 20 MPa. Fig. 1

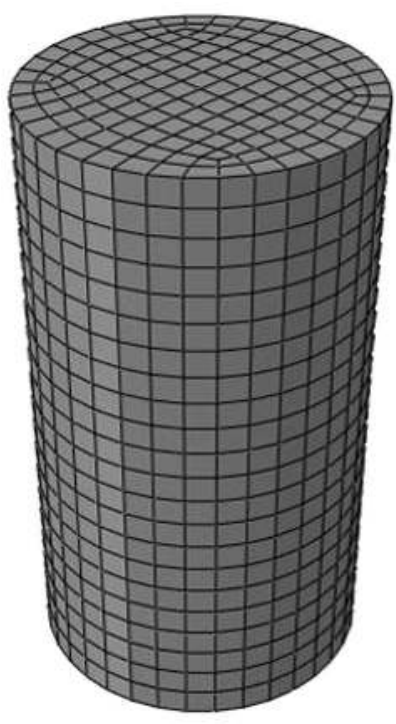

(a)

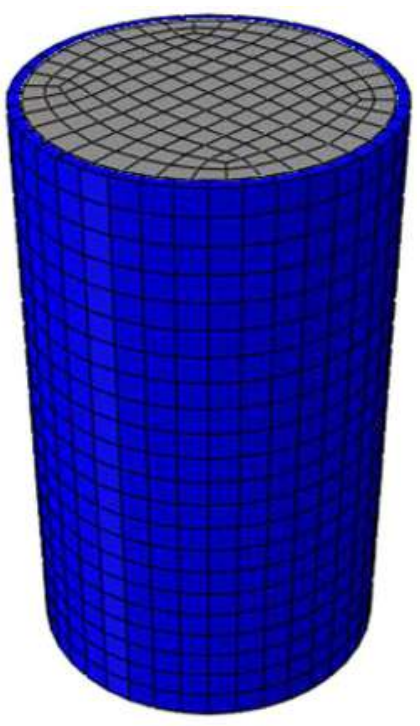

(b)
Fig. 1. Simulated specimens for Multon-Toutlemonde (2006) tests: (a) unconfined case; (b) confined case illustrates the simulated specimens for both unconfined and confined conditions.

First calibrated was the case of free expansion; see Table 1 for the calibration parameters. For simplicity, only 2 aggregate sizes were considered in this study: $D=9 \mathrm{~mm}$ for $85 \%$ of aggregates, and $D=4.2 \mathrm{~mm}$ for $15 \%$. The actual aggregate size distribution could not be used because for most tests it was not reported; only the minimum and maximum sizes were reported.

Because there are no externally introduced stresses, only the relative volume change due to ASR is calculated; i.e., $3 \epsilon_{V}=\epsilon_{\text {axial }}+$ $2 \epsilon_{\text {radial }}$. Figs. 2(a-c) compare the measurements and simulations based on calibration for Case c, volume expansion. The predicted radial and axial expansions are seen to be quite close.

Although, in absence of load and radial confinement, the initial progress of ASR and of the initial microcracking damage must be statistically isotropic, later on the measured strains are highly anisotropic. That would surely not occur if the specimen were a sphere. For the cylinder, the explanation of strain anisotropy is that the strains include smeared macroscopic cracking engendered by the ASR expansion. The prevailing macrocracks with the biggest opening width ought to be those that maximize the rate of release of strain energy from the whole specimen, and this release depends on the specimen shape. In the test cylinder, the maximizing direction is mostly radial, and the radial macrocracks of wider opening doubtless contribute a large part of the measured overall axial strain; consult the cracking patterns in Fig. 5(a), which are calculated by using microplane model M7 with creep (Caner and Bažant 2013a, b), coupled with the crack band model.

The width of the crack band, which represents the material characteristic length $l_{0}$, is important to prevent spurious cracking localization. It was $15 \mathrm{~mm}$ in the present simulations. Because what matters is the average strain across the crack band, the lowest order elements are suitable. Square elements consisting of four constant strain triangles were used for the band.

The cracking pattern in Fig. 5 could not be obtained if all the elements were considered to contain reactive silica. Of course, in reality not all the aggregates are reactive. As already mentioned, $50 \%$ of all finite elements, each imagined to contain at least one aggregate, were randomly chosen to be reactive.

Although the present model was calibrated only for the radial strain in load-free unconfined specimens (a strain that is unaffected by cracking), the microplane model with the crack band model provided good predictions for the axial and volumetric strains, which are strongly affected by cracking. This fact highlights the importance of using a material model that reproduces fracture behavior correctly.

Next, using the same material parameters, the Multon and Toutlemonde's (2006) tests with various loadings and confinements are predicted. Figs. 3 and 4 show that the computer predictions closely match the measured axial and radial strains. In particular, they confirm that the present model can predict the so-called $e x$ pansion transfer, i.e., the loading-induced transfer of ASR expansion to another direction.

Table 1. Calibration Parameters for the Experimental Sets That Have Been Used in This Study

\begin{tabular}{lccrrr}
\hline & & \multicolumn{3}{c}{ Parameters } \\
\cline { 3 - 6 } Author & Material & $b_{0}\left(\mathrm{~N} / \mathrm{m}^{2}\right.$ day $)$ & $v_{0}(\%)$ & \multicolumn{1}{c}{$\beta$} & $c_{s}\left(\mathrm{~kg} / \mathrm{m}^{3}\right)$ \\
\hline Multon and Toutlemonde (2006) & Concrete & $5.3 \times 10^{-14}$ & 0.75 & $3.2 \times 10^{6}$ & 700 \\
Ben Haha (2006) & Concrete & $3.5 \times 10^{-14}$ & 0.5 & $4 \times 10^{6}$ & $7.4 \times 10^{4}$ \\
Ben Haha (2006) & Mortar & $3.5 \times 10^{-14}$ & 0.5 & $4.5 \times 10^{6}$ & 700 \\
Poyet et al. (2006) & Mortar & $1.5 \times 10^{-13}$ & 1 & $4.5 \times 10^{6}$ & 590 \\
\hline
\end{tabular}



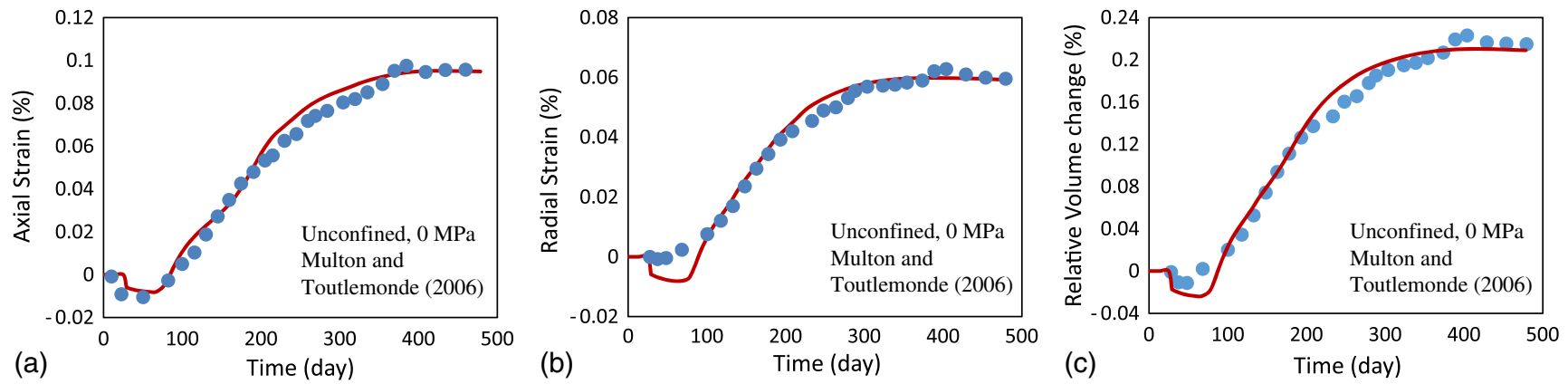

Fig. 2. Expansion due to ASR for unconfined unloaded specimen: (a) axial expansion, (b) radial expansion, (c) relative volume expansion $\left(\epsilon_{\text {axial }}+2 \epsilon_{\text {axial }}\right)$
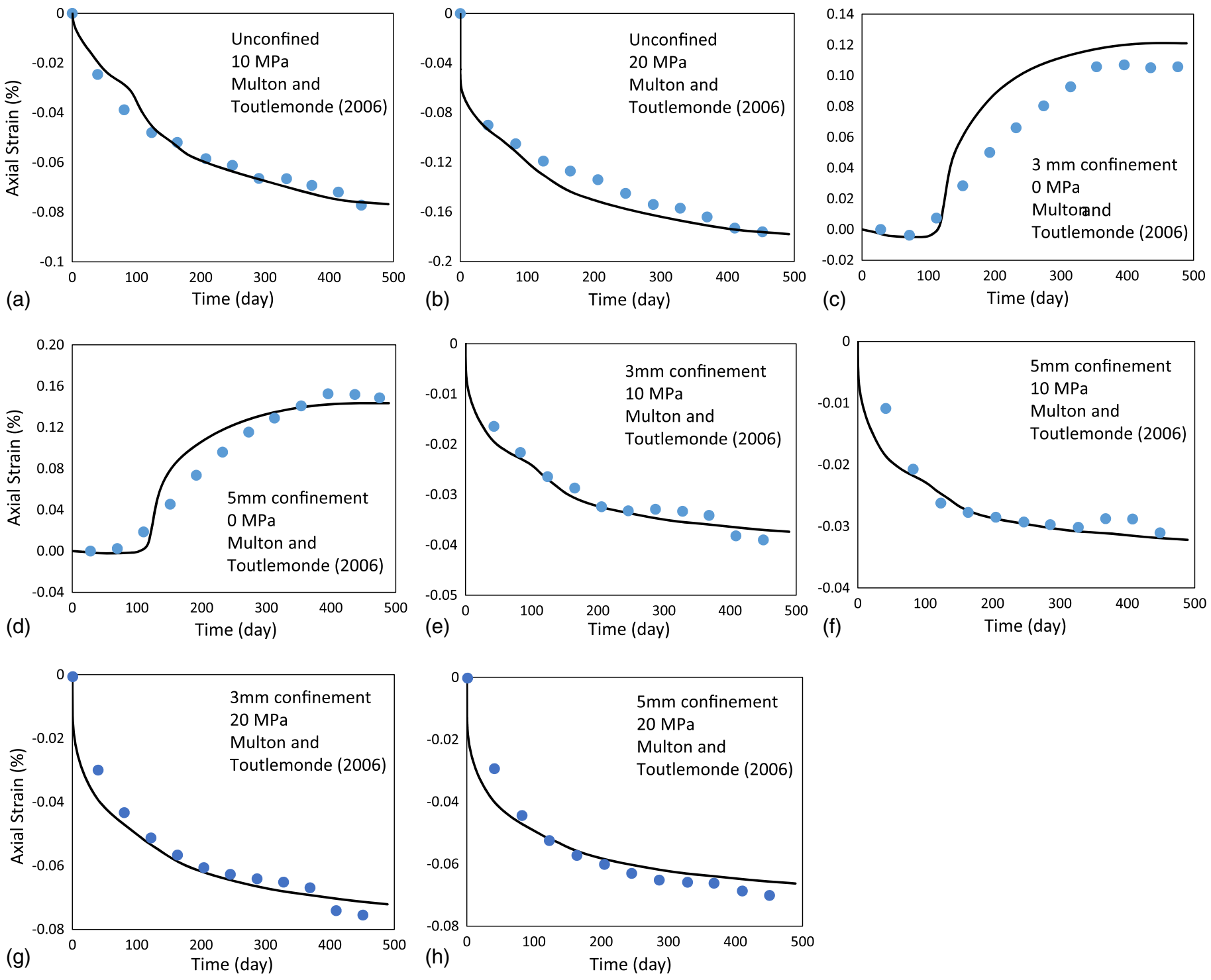

Fig. 3. Axial strain-reaction time for (a) unconfined under $10 \mathrm{MPa}$ axial load; (b) unconfined under $20 \mathrm{MPa}$ axial load; (c) $3 \mathrm{~mm}$ confinement under no axial load; (d) $5 \mathrm{~mm}$ confinement under no axial load; (e) $3 \mathrm{~mm}$ confinement under $10 \mathrm{MPa}$ axial load; (f) $5 \mathrm{~mm}$ confinement under $10 \mathrm{MPa}$ axial load; (g) $3 \mathrm{~mm}$ confinement under $20 \mathrm{MPa}$ axial load; (h) $5 \mathrm{~mm}$ confinement under $20 \mathrm{MPa}$ axial load

In the cylinders confined by tubular steel envelopes, the concrete was considered to slide against the steel. The friction coefficient was not reported. In the simulations it was assumed to be 0.15 .
In this study the effect of confining pressure on gel pressure has been neglected. This effect can be considered using the so-called Skempton pore pressure coefficient, $B$. For undrained condition, this coefficient can be defined as (Detournay and Cheng 2014) 

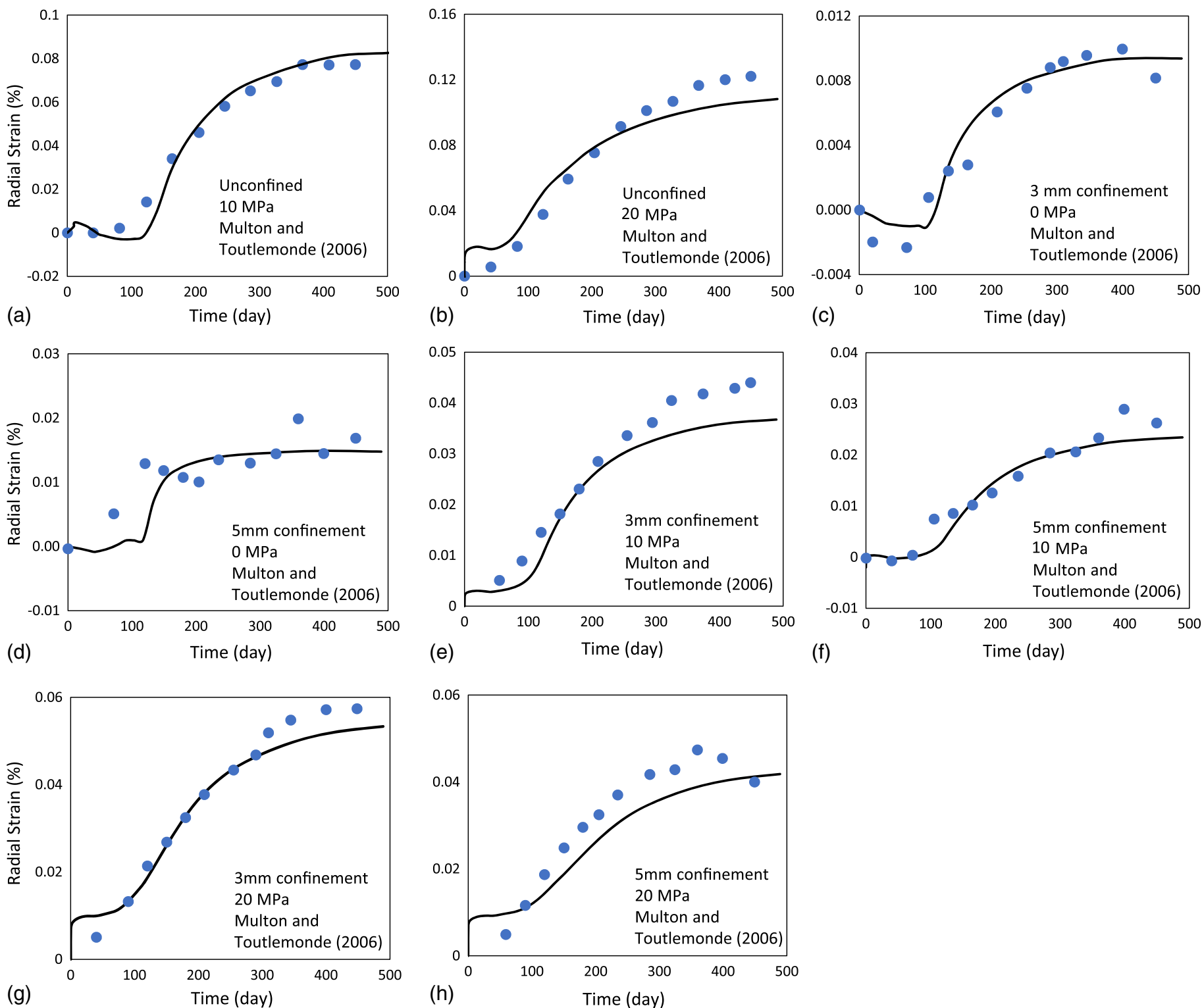

Fig. 4. Radial strain-reaction time for (a) unconfined under $10 \mathrm{MPa}$ axial load; (b) unconfined under $20 \mathrm{MPa}$ axial load; (c) 3 mm confinement under no axial load; (d) $5 \mathrm{~mm}$ confinement under no axial load; (e) $3 \mathrm{~mm}$ confinement under $10 \mathrm{MPa}$ axial load; (f) $5 \mathrm{~mm}$ confinement under $10 \mathrm{MPa}$ axial load; (g) $3 \mathrm{~mm}$ confinement under $20 \mathrm{MPa}$ axial load; (h) $5 \mathrm{~mm}$ confinement under $20 \mathrm{MPa}$ axial load

$$
B=\frac{\Delta p}{\Delta P}
$$

where $\Delta p=$ change of ASR gel pressure; and $\Delta P=$ same confining pressure. As this equation suggests, the pressure of the ASR gel would increase as the confining pressure increases. The Skempton coefficient is negligible for undamaged concrete, but as the specimen is damaged and gets weaker the value of this coefficient may become larger and more significant. This phenomenon may be the reason of the slight underestimation of the ASR expansion in the cases where the confining pressure is significant [Figs. 4(b, g, and h)].

The damage and cracking pattern for various stress states are rather different, as seen in Fig. 5. For the unconfined load-free case, the cracks favor no direction. Adding an axial compressive load will prevent damage bands, or macrocracks, in the axial direction and will force the cracks to propagate primarily radially [Fig. 5(b)]. In other words, an axial load at no lateral confinement will cause the ASR-induced expansion to prefer the direction normal to the load, i.e., radial.

The present model can capture all of the aforementioned cracking patterns and yield good agreement with the strains measured in (Larive 1997).

\section{Degradation of Mechanical Properties Caused by ASR}

As shown by many studies, the ASR-induced expansion produces microcracks and cracks that weaken the concrete (Swamy and Al-Asali 1988; Ben Haha 2006; Ben Haha et al. 2007; Clark 1990; Cusatis et al. 2014; Monette et al. 2000; Ono 1990; Siemes and Visser 2000; Swamy and Al-Asali 1986; Swamy 2002). In this paper the effect of ASR on (1) compressive strength, (2) tensile strength, and (3) Young's modulus is investigated. The model predictions are compared to the experimental data of Ben Haha 


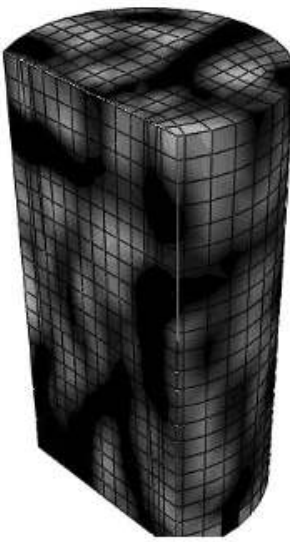

(a)

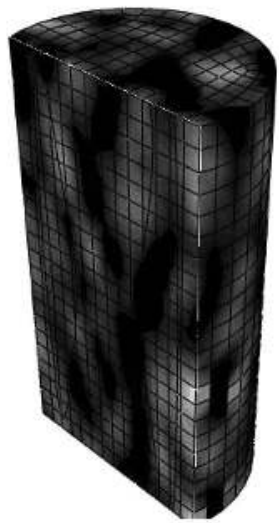

(b)

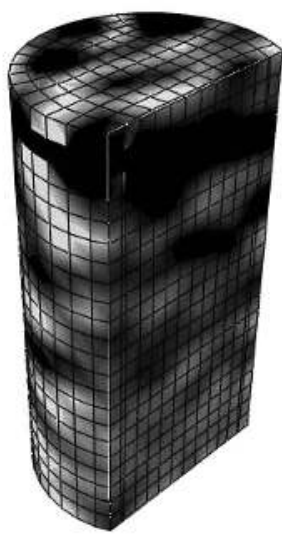

(c)

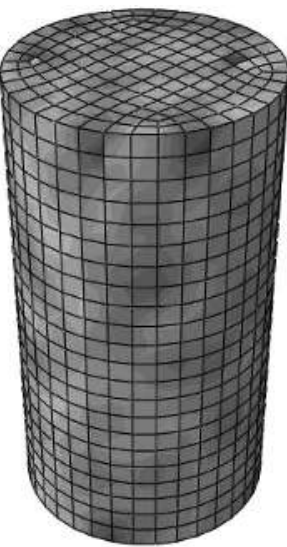

(d)

Fig. 5. Cracking patterns for different stress states: (a) unconfined-unloaded; (b) radial confined-unloaded; (c) unconfined axially loaded; (d) confined axially loaded

(Ben Haha 2006; Ben Haha et al. 2007) from his accelerated tests of concrete prisms of dimensions $70^{2} \times 280 \mathrm{~mm}$, submerged in water. Because the autogenous shrinkage and the swelling were not measured, they are neglected, although they might have had nonnegligible effects, particularly at short times.

First the model is calibrated to fit Ben Haha's measured ASRinduced expansion (see Table 1 for the calibration parameters). As mentioned previously, $85 \%$ of aggregates are considered to have the size of $D=10 \mathrm{~mm}$, and $15 \%$ to have $D=4.3 \mathrm{~mm}$. Fig. 6(a) shows the simulated specimen and Fig. 6(b) compares the experimental and calculated ASR-induced expansions using the aforementioned fitting parameters. Having the model calibrated to predict the measured expansion, its power can be examined in predicting the effect of ASR on the mechanical properties. To this end, the authors analyze the effects of axial load, tensile or compressive, at different stages of the ASR.

Starting with a compressive axial force, it is increased uniformly to reach the strength limit and failure in approximately $10 \mathrm{~min}$. Although it seems logical that ASR reduces the compressive strength because of microcracking and macrocracking, there is a discrepancy among various experimenters. For instance, Clark (1990) and Ono (1990) found that ASR can decrease the compressive strength by up to $40 \%$, while Monette (2000) found the compressive strength not to be affected significantly. However, in this regard it must be noted that the ASR and the aging due to cement hydration have opposite effects, the former decreasing the strength and the latter increasing it. Another source of increase may be the filling of pores outside the aggregate piece by calcified gel. These competing effects must be the root cause of the discrepancy.

To isolate the ASR effect, the relative compressive strengths of specimens with and without the reactive aggregates are considered. Fig. 7(a) shows the compressive strength ratio of ASR affected to unaffected concrete at various reaction times, and shows that the compressive strength decreases by approximately 5\% due to ASR. The comparison also demonstrates that the present ASR model with microplane model M7 provides a good match of the experimental data.

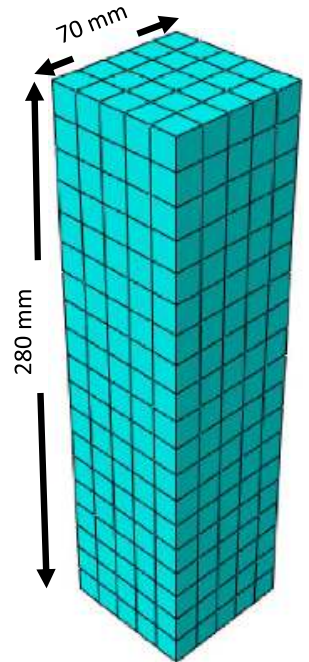

(a)

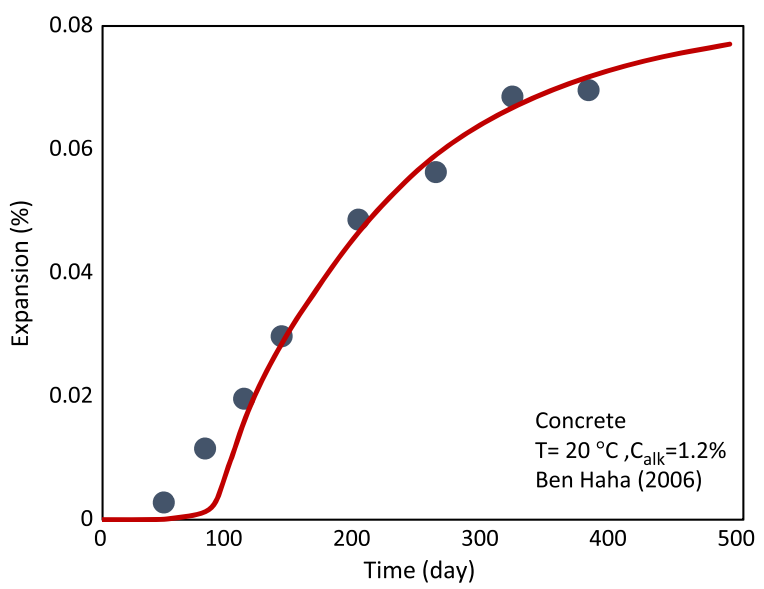

(b)

Fig. 6. Calibrating ASR-induced expansion for concrete specimen: (a) simulated specimen; (b) experimental versus simulated ASR-induced expansion 

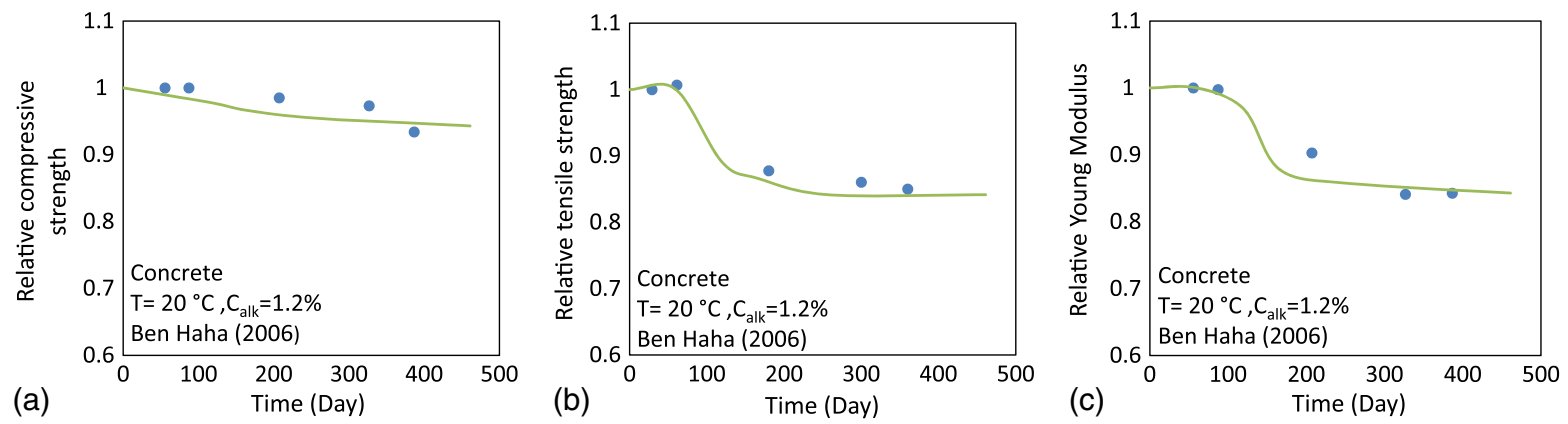

Fig. 7. Mechanical properties change due to ASR reaction: (a) compressive strength of affected concrete versus unaffected one; (b) tensile strength of affected concrete versus unaffected one; (c) Young's modulus of affected concrete versus unaffected one

To study the tensile strength, tensile load at various times is applied, increasing at constant rate to reach the strength limit in approximately $10 \mathrm{~min}$. While there are disagreements about the compressive strength reduction, virtually all the experiments concluded that ASR reduces the tensile strength (Swamy and Al-Asali 1988, 1986; Swamy 2002). Different experimenters nevertheless reported very different reduction percentages. Siemes and Visser (2000) investigated 25 bridges and found reductions by up to $85 \%$.

To simulate the reduction, the same procedure as described for compressive strength is used. Fig. 7(b) shows the ratios of affected to unaffected tensile strength measured at various times. In this study, the ASR expansion is found to decrease the tensile strength by $15 \%$.

Lastly, consider Young's modulus $E$, which is readily extracted from the simulations of loading up to the compressive strength. The ratios of $E$-values at various reaction times to the unaffected $E$-values are shown in Fig. 7(c). As seen, Young's modulus is predicted to decrease by $15 \%$, which agrees with the decrease measured by Ben Haha.

It must be emphasized that the experimental data analyzed in this study are specific to two particular concretes. The behavior of other concretes may be very different. That is why a realistic prediction model has been developed.

\section{Effect of Alkali Content on ASR-Induced Expansion}

The alkali content can have a big effect on the ASR reaction (Guédon-Dubied et al. 2000; Sibbick and Page 1992). The availability of alkali ions and hydroxyl ions is what controls ASR kinetics. In Part I, $f_{\text {alk }}$ was defined for this purpose and used to calculate the gel mass in one aggregated grain: $w_{b g}=(\pi / 6)\left(D^{3}-\right.$ $\left.8 z^{3}\right) c_{s} f_{\text {alk }} m_{g} / m_{s}$ [Eq. (3) of Part I]. However, the alkali content was considered to be high enough for ASR progress, and assumed the alkali ions to be in sufficient supply for complete reaction, in which case $f_{\text {alk }}=1$ was used.

Often it is necessary to assess ASR for concrete with a lower alkali content that is insufficient for a complete reaction. In that case $f_{\text {alk }}<1$ must be used. To this end, the following empirical equation, which has led to good data fits, is introduced:

$$
f_{\mathrm{alk}}=\left(\frac{C_{\mathrm{alk}}-C_{\mathrm{alk}}^{0}}{C_{\mathrm{alk}}^{*}-C_{\mathrm{alk}}^{0}}\right)^{1 / 3}
$$

where $C_{\mathrm{alk}}=$ alkali content (ratio of the mass of alkali to cement mass); $C_{\mathrm{alk}}^{0}=$ alkali content at which ASR stops; and $C_{\mathrm{alk}}^{*}=$ alkali content at which alkali ions are sufficient for complete reaction.
In this study, $C_{\mathrm{alk}}^{0}=0.1 \%$ was assumed and $C_{\mathrm{alk}}^{*}$ was set equal $1.25 \%$ for concrete and $1 \%$ for mortar because $c / a$ is higher in mortar and the alkali content is calculated as a function of cement ( $c / a=$ cement to aggregate ratio, by mass). It would be better to find an empirical equation for $C_{\mathrm{alk}}^{*}$ as a function of $c / a$, but experimental data are lacking.

In regard to the effect of alkali content, two sets of experiments are considered. The first is the same as that already considered for examining the ASR effect on mechanical properties, characterized by the calibration parameters in Table 1 . The second is Ben Haha's (2006) and Ben Haha et al.'s (2007) set of tests of saturated mortar prisms of size $40 \times 40 \times 160 \mathrm{~mm}$, with aggregate size $\leq 3 \mathrm{~mm}$ [Fig. 8(a)]. Because of lack of information, possible autogenous shrinkage or swelling was ignored. The present model was first calibrated by fitting Ben Haha's test results for $C_{\mathrm{alk}}=$ $1.2 \%$ and temperature $=20^{\circ} \mathrm{C}$. Fig. 8(b) compares the experimental results with the predictions based on the calibration parameters listed in Table 1; $85 \%$ of aggregates had the size of $D=2 \mathrm{~mm}$, and $15 \%$ had $D=0.75 \mathrm{~mm}$. Thanks to symmetries, only one $1 / 8$ of each prism had to be simulated.

After this calibration, the effect of alkali content on the ASR expansion is predicted. The experimental and predicted results for different alkali contents are compared in Fig. 9(a) for concrete, and in Fig. 9(b) for mortar. Good agreement is seen. Further tests of alkali content effect conducted at different temperatures are analyzed in the next section.

\section{Effect of Temperature on ASR-Induced Expansion}

Like all chemical reactions, ASR kinetics changes significantly with temperature (Jensen et al. 1982; Jones 1988; Olafsson 1986; Larive 1997; Salomon and Panetier 1994; Swamy and Al-Asali 1986; Pleau et al. 1989), and this affects the ASR-induced expansion and damage. The temperature effect is considered to follow the Arrhenius equation for permeability, $a_{s}$, of water through ASR gel, for initial diffusivity, $C_{i}^{0}$, of cement mortar around the aggregate, and for permeability, $b$, of the ASR gel:

$$
\begin{aligned}
a_{s} & =a_{s}^{0} \exp \left(\frac{E_{a}}{R T_{0}}-\frac{E_{a}}{R T}\right) \\
C_{i}^{0} & =C_{i}^{\text {ref }} \exp \left(\frac{E_{C}}{R T_{0}}-\frac{E_{C}}{R T}\right) \\
b & =b_{0} \exp \left(\frac{E_{b}}{R T_{0}}-\frac{E_{b}}{R T}\right)
\end{aligned}
$$




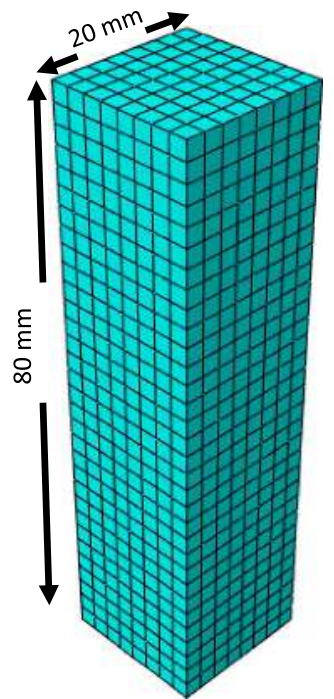

(a)

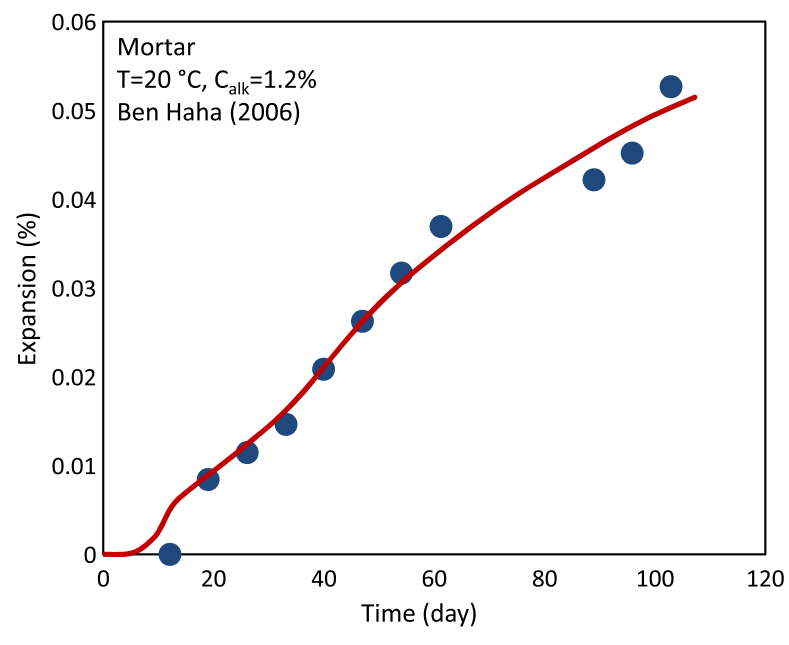

(b)

Fig. 8. Calibrating ASR-induced expansion for mortar specimen: (a) simulated specimen; (b) experimental versus simulated ASR-induced expansion
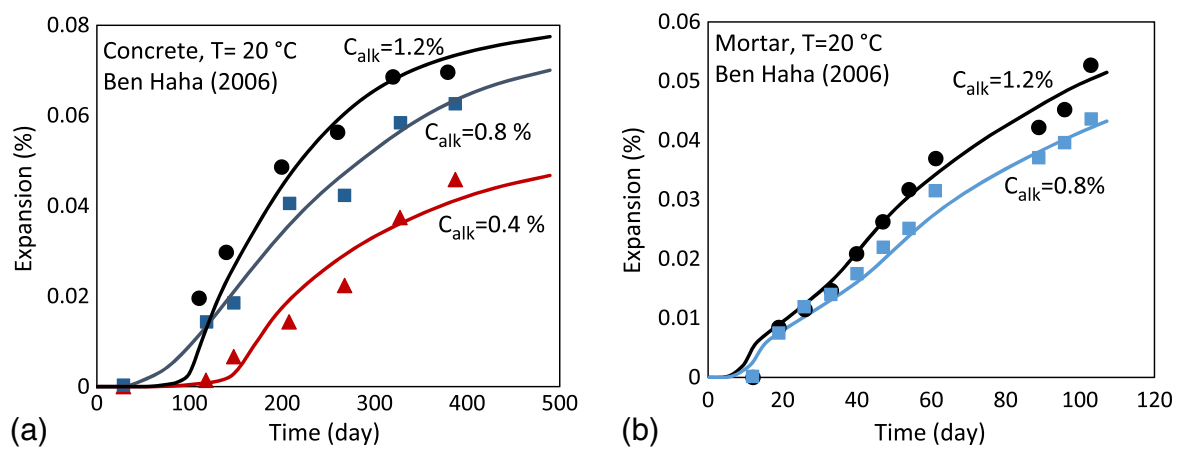

Fig. 9. ASR expansion for concrete and mortar specimens with different alkali contents: (a) experimental versus simulated results for concrete specimens with different alkali contents; (b) experimental versus simulated results for mortar specimens with different alkali content

here $T=$ current absolute temperature; $R=$ universal gas constant; $a_{s}^{0}, C_{i}^{\text {ref }}, b_{0}=$ values at reference temperature $T_{0}=293 \mathrm{~K}$; and $E_{a}$, $E_{C}, E_{b}=$ corresponding activation energies. The values used in the computations were $E_{a}=E_{C}=42.5 \mathrm{~kJ} / \mathrm{mol}$ and $E_{b}=45 \mathrm{~kJ} / \mathrm{mol}$. The temperature effects on $C_{i}^{0}$ and $a_{s}$ translate into temperature effects on the rate of ASR gel production [Eq. (5) of Part I]. Note that if parameter $\eta_{w}$ were kept constant, the foregoing temperature effects would also apply to the characteristic time $\tau_{i}$ of water imbibition. However, because the temperature effect on $\tau_{i}$ is expected to be approximately the same as on $C_{i}^{0}, \eta_{w}$ is modified such that $w_{i} \eta_{w}$ be approximately constant [Eq. (5) of Part I]. Therefore

$$
\eta_{w}=\eta_{w}^{0}\left(\frac{E_{\eta}}{R T_{0}}-\frac{E_{\eta}}{R T}\right)^{-1}
$$

where $\eta_{w}^{0}=$ value at reference temperature; and $E_{\eta}=$ corresponding activation energy, and $E_{\eta}=E_{a} / 2$ was used.

For the experimental comparisons and calibrations, Ben Haha's tests (Ben Haha 2006; Ben Haha et al. 2007) were used again to predict the effect of temperature on the role of alkali using the same parameters as calibrated for $T_{0}$; Figs. 10(a and b) for concrete and mortar prisms. The fits are seen to be quite close.
Finally, consider the combined effect of alkali content and temperature when both are different from the calibration experiments. Figs. 11( $\mathrm{a}$ and b) compare the experimental and simulated results for concrete and mortar prisms at $T=40^{\circ} \mathrm{C}$, with different alkali contents. Fig. 11(c) demonstrates the same for $T=60^{\circ} \mathrm{C}$.

\section{Effect of Drying on ASR}

Availability of water is crucial for ASR. No water, no ASR. The more water, the greater the ASR damage. The role of water is fundamental for three reasons (Bažant and Steffens 2000):

- The pore water acts as the necessary transport medium for the mass transport of hydroxyl and alkali ions required by the reaction;

- The expansion of the gel is essentially governed by the imbibition of water; and

- For the reaction to continue, water must be supplied by macrodiffusion through the pores of concrete.

Many researchers demonstrated that if the water supply is decreased by drying, the ASR expansion diminishes (Kurihara and Katawaki 1989; Larive et al. 2000; Olafsson 1986; Poyet et al. 2006; Tomosawa et al. 1989; Vivian 1981). Below some critical relative humidity. $h^{\circ}$, depending on temperature, the ASR stops. 

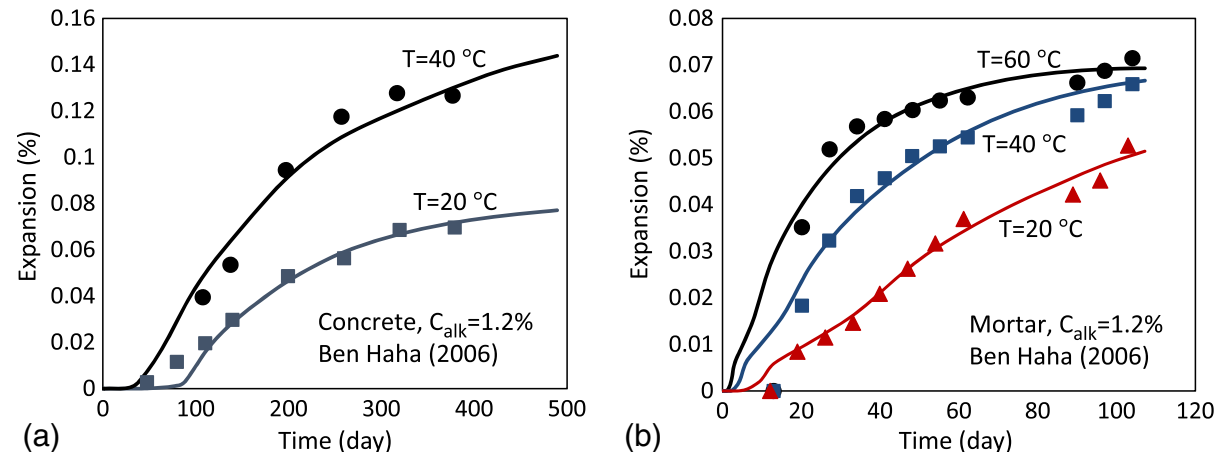

Fig. 10. ASR expansion for concrete and mortar specimens with different temperatures: (a) experimental versus simulated results for concrete specimens with different temperatures; (b) experimental versus simulated results for mortar specimens with different temperatures
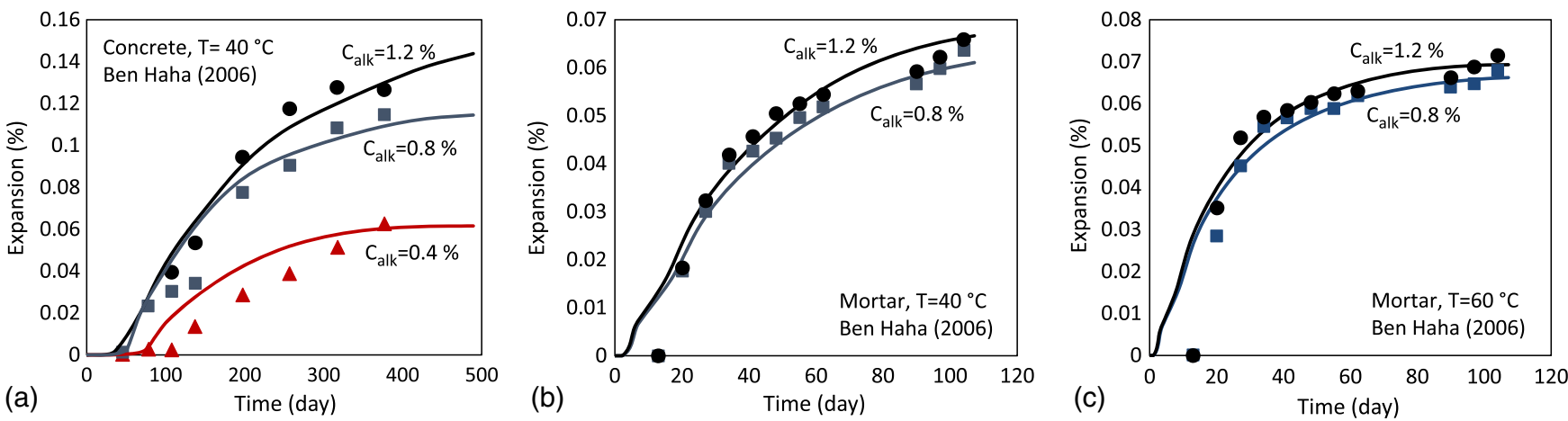

Fig. 11. ASR expansion for specimens with different temperature and alkali contents with respect to calibrated one: (a) simulated results for concrete specimens at $T=40^{\circ} \mathrm{C}$; (b) simulated results for mortar specimens at $T=40^{\circ} \mathrm{C}$; (c) simulated results for mortar specimens at $T=60^{\circ} \mathrm{C}$

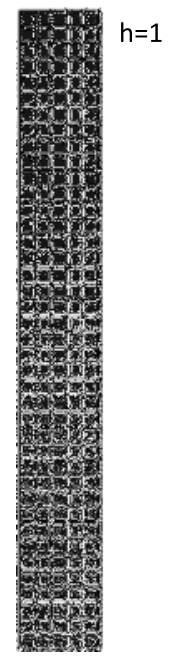

(a)

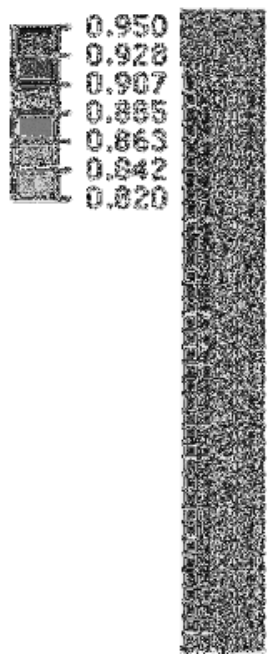

(b)

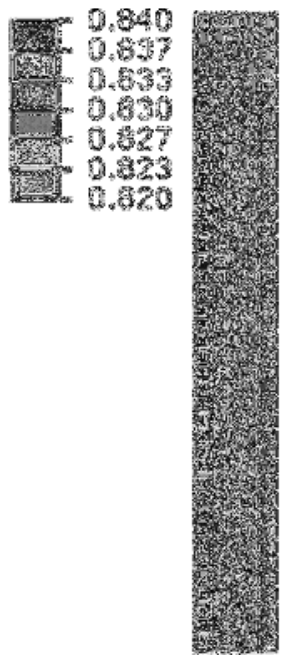

(c)

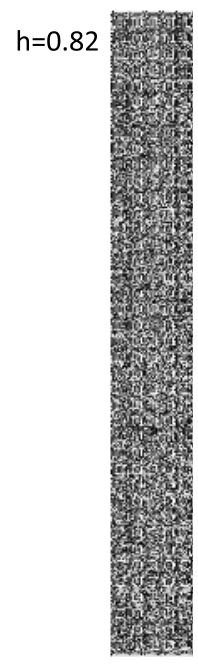

(d)

Fig. 12. Drying procedure: (a) $t=0$ day; (b) $t=8$ days; (c) $t=20$ days; (d) $t=60$ days

For instance, Nilsson (1983) reported that the ASR stops if the humidity drops below $h^{\circ}=80 \%$; according to Ludwig (1989), $h^{\circ}=80-85 \%$ at $T=20^{\circ} \mathrm{C}$; and according to Olafson (1986), $h^{\circ}=80 \%$ for $T=23^{\circ} \mathrm{C}$ and $h^{\circ}=75 \%$ for $T=38^{\circ} \mathrm{C}$.

A decrease of water supply not only reduces the ASR swelling, but also drastically reduces the diffusivity of cement paste or mortar around the reactive aggregate and thus decelerates the swelling, even by one or two orders of magnitude. To model it, Bažant and Najjar's (1972) empirical equation (embodied in fib Model Code 2010) was adopted for the dependence of local diffusivity $C_{i}$ on moisture in the mortar or cement paste around the aggregate 

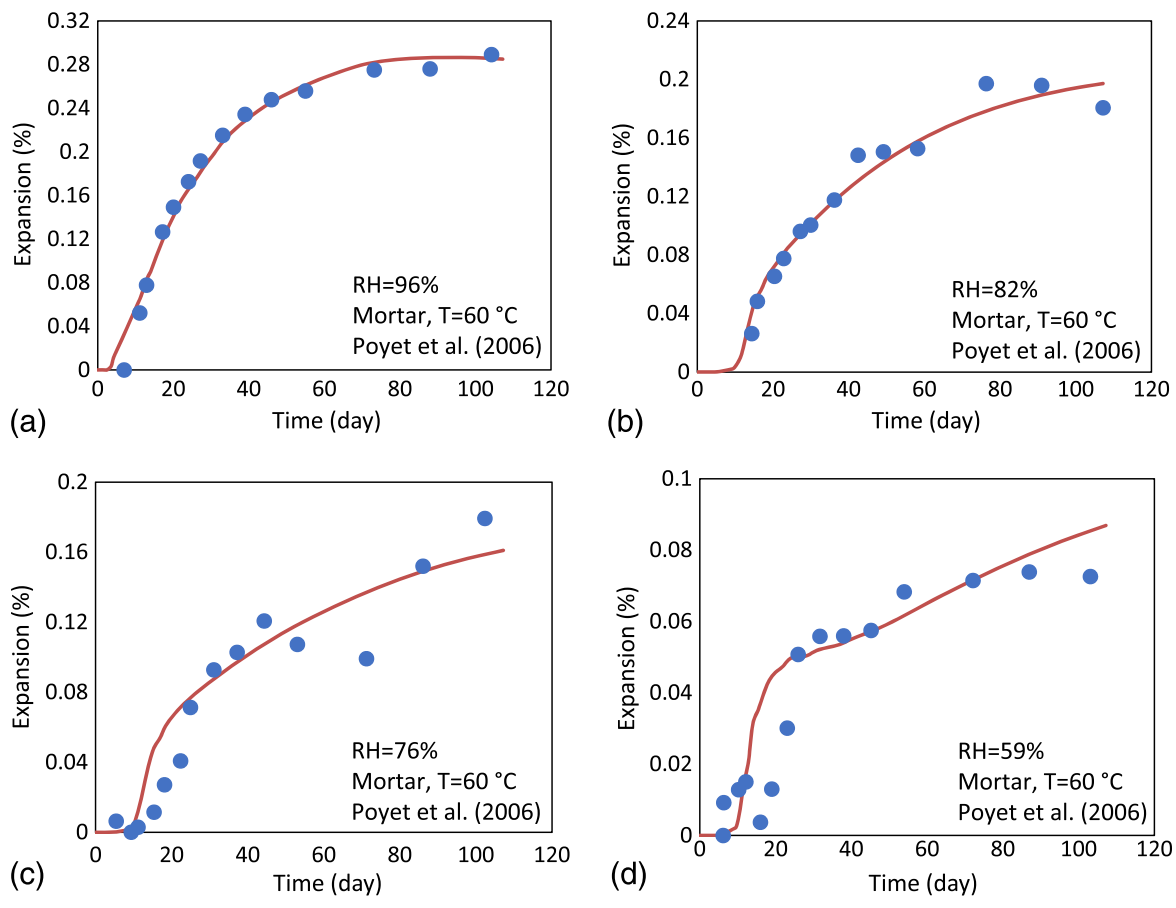

Fig. 13. ASR expansion at different environmental humidity ratios: (a) $\mathrm{RH}=96 \%$; (b) $\mathrm{RH}=82 \%$; (c) $\mathrm{RH}=76 \%$; (d) $\mathrm{RH}=59 \%$

$$
C_{i}=C_{i}^{\mathrm{sat}}\left[\alpha_{0}+\frac{1-\alpha_{0}}{1+\left(\frac{1-h}{1-h}\right)^{n}}\right]
$$

where $C_{i}^{\text {sat }}=$ value of $C_{i}$ at $h=100 \%$; and $\alpha_{0}, n$ and $h^{*}$ are empirical constants. If the concrete is exposed to external drying, numerical solution of Bažant and Najjar's (1972) differential equation for global water diffusion through unsaturated concrete is inevitable

$$
\dot{h}=\nabla \cdot\left(C_{g} \nabla h\right)+\dot{h}_{\text {self }}
$$

where $h_{\text {self }}=$ pore relative humidity due to self-desiccation (caused by hydration); and $C_{g}=$ global diffusivity, which is assumed to depend on $h$ in a way similar to Eq. (7), i.e.

$$
C_{g}=C_{g}^{\mathrm{sat}}\left[\alpha_{0}+\frac{1-\alpha_{0}}{1+\left(\frac{1-h}{1-h}\right)^{n}}\right]
$$

where $C_{g}^{\text {sat }}=C_{g}$ at saturation. Fig. 12 illustrates one example of predicted drying evolution for specimen with external relative humidity $h=0.82$.

Another important issue is the significant effect of shrinkage when the concrete undergoing ASR is exposed to drying. In that case, $h$ varies both in space and time. Thus, in different regions, the ASR gel swells nonuniformly, more in the specimen core than near the surface. The local free drying shrinkage, $\epsilon_{s h}$, which is also nonuniform, may be assumed to be approximately linear in $h$ (Jirásek and Bažant 2002), i.e.

$$
d \epsilon_{s h}=K_{s h} d h
$$

where $K_{s h}=0.004$ (empirical constant); $C_{g}^{\text {sat }}=3 \mathrm{~mm}^{2} /$ day; $n=3 ; h^{*}=0.76$; and $\alpha_{0}=0.07$. Here, the approximate formulas for average drying shrinkage in the cross section (Bažant and Baweja 2000; Bažant et al. 2015) are insufficient.

To verify the ASR model for drying concrete, the experiments of Poyet et al. (2006) conducted at various environmental relative humidity ratios are used. The specimens were mortar cylinders,
$16 \mathrm{~cm}$ in length and $2 \mathrm{~cm}$ in diameter, and the tests were done at $T=60^{\circ} \mathrm{C}$. Table 1 lists the calibration parameters. Again, $85 \%$ of aggregates were considered to have $D=2 \mathrm{~mm}$, and $15 \%$ to have $0.75 \mathrm{~mm}$. Fig. 13(a) shows the evolution of expansion in time for sealed condition and and Figs. 13(b-d) compares the experimental and simulated ASR-induced expansions at various environmental humidity ratios.

\section{Closing Comment}

Close agreement with the main data on the ASR effects on laboratory specimens gives the promise that the present ASR model would allow realistic predictions of the multidecade evolution of the ASR damage in large structures.

\section{Acknowledgments}

Partial financial supports from the NEUP Program of the U.S. Department of Energy under grant DE-AC07-05/D14517, and from the U.S. National Science Foundation under grant CMMI-1153494, both to Northwestern University, are gratefully acknowledged.

\section{References}

Ahmed, T., Burley, E., and Rigden, S. (1999). "The effect of alkali-silica reaction on the fatigue behaviour of plain concrete tested in compression, indirect tension and flexure." Mag. Concr. Res., 51(6), 375-390.

Alnaggar, M., Cusatis, G., and Di Luzio, G. (2013). "Lattice discrete particle modeling (LDPM) of alkali silica reaction (ASR) deterioration of concrete structures." Cem. Concr. Compos., 41, 45-59.

Bažant, Z., Hubler, M., and Wendner, R. (2015). "Model B4 for creep, drying shrinkage and autogenous shrinkage of normal and high-strength concretes with multi-decade applicability." Mat. .Struct., 48(4), 753-770.

Bažant, Z., and Najjar, L. (1972). "Nonlinear water diffusion in nonsaturated concrete." Matériaux et Constr., 5(1), 3-20. 
Bažant, Z. P., and Baweja, S. (2000). "Creep and shrinkage prediction model for analysis and design of concrete structures: Model B3." ACI Spec. Publ., 194, 1-84.

Bažant, Z. P., and Oh, B. H. (1983). "Crack band theory for fracture of concrete." Matériaux et Constr., 16(3), 155-177.

Bažant, Z. P., and Planas, J. (1997). Fracture and size effect in concrete and other quasibrittle materials, Vol. 16, CRC Press, Boca Raton, FL.

Bažant, Z. P., and Steffens, A. (2000). "Mathematical model for kinetics of alkali-silica reaction in concrete." Cem. Concr. Res., 30(3), 419-428.

Ben Haha, M. (2006). "Mechanical effects of alkali silica reaction in concrete studied by SEM-image analysis." Ph.D. thesis, EPFL, Lausanne, Switzerland.

Ben Haha, M., Gallucci, E., Guidoum, A., and Scrivener, K. L. (2007). "Relation of expansion due to alkali silica reaction to the degree of reaction measured by SEM image analysis." Cem. Concr. Res., 37(8), 1206-1214.

Caner, F. C., and Bažant, Z. P. (2013a). "Microplane model M7 for plain concrete. I: Formulation.” J. Eng. Mech., 10.1061/(ASCE)EM.1943 -7889.0000570, 1714-1723.

Caner, F. C., and Bažant, Z. P. (2013b). "Microplane model M7 for plain concrete. II: Calibration and verification.” J. Eng. Mech., 10.1061 /(ASCE)EM.1943-7889.0000571, 1724-1735.

Červenka, J., Bažant, Z. P., and Wierer, M. (2005). "Equivalent localization element for crack band approach to mesh-sensitivity in microplane model." Int. J. Numer. Methods Eng., 62(5), 700-726.

Clark, L. (1990). "Structural aspects of alkali-silica reaction." Struct. Eng. Rev., 2(2), 81-87.

Cusatis, G., Alnaggar, M., and Rezakhani, R. (2014). "Multiscale modeling of alkali silica reaction degradation of concrete." Proc., RILEM Int. Symp. on Concrete Modelling-CONMOD, RILEM International, 431-438.

Detournay, E., and Cheng, A. H. D. (2014). "Fundamentals of poroelasticity." Comprehensive rock engineering: Principles, practice and projects, J. A. Hudson, ed., Vol. 2, Pergamon Press, Oxford, U.K., 113-172.

Gravel, C., Ballivy, G., Khayat, K., Quirion, M., and Lachemi, M. (2000). "Expansion of AAR concrete under triaxial stresses: Simulation with instrumented concrete block." Proc., 11th Int. Conf. on Alkali Aggregate Reaction, ICON/CANMET, 949-958.

Guédon-Dubied, J., Cadoret, G., Durieux, V., Martineau, F., Fasseu, P., and Van Overbecke, V. (2000). "Study on tournai limestone in Antoing Cimescaut quarry-Petrological, chemical and alkali reactivity approach." Proc., 11th Int. Conf. on AAR in Concrete, ICON/CANMET, 335-344.

Jensen, A. D., Chatterji, S., Christensen, P., Thaulow, N., and Gudmundsson, H. (1982). "Studies of alkali-silica reaction. Part I: A comparison of two accelerated test methods." Cem. Concr. Res., 12(5), 641-647.

Jirásek, M., and Bažant, Z. P. (2002). Inelastic analysis of structures, Wiley, New York.

Jones, T. (1988). "New interpretation of alkali-silica reaction and expansion mechanisms in concrete." Chem. Ind., 40-4.

Kurihara, T., and Katawaki, K. (1989). "Effects of moisture control and inhibition on alkali silica reaction." Proc., 8th Int. Conf. on Alkali-Aggregate Reaction, Elsevier, Amsterdam, Netherlands, 629-634.

Larive, C. (1997). "Apports combinés de l'expérimentation et de la modélisation à la compréhension de l'alcali-réaction et de ses effets mécaniques." Ph.D. thesis, École Nationale des Ponts et Chaussees, Paris.
Larive, C., Laplaud, A., and Coussy, O. (2000). "The role of water in alkalisilica reaction." Proc., 11th Int. Conf. on Alkali Aggregate Reaction, ICON/CANMET, 61-69.

Larive, C., Laplaud, A., and Joly, M. (1996). "Behavior of AAR-affected concrete: Experimental data." Proc., 10th Int. Conf. on AAR, AARC, Anglesea, Australia, 670-677.

Ludwig, U. (1989). "Effects of environmental conditions on alkali-aggregate reaction and preventive measures." Proc., 8th Int. Conf. on Alkali Aggregate Reaction in Concrete, Elsevier, Amsterdam, Netherlands, 583-596.

Monette, L., Gardner, J., and Grattan-Bellew, P. (2000). "Structural effects of the alkali-silica reaction on non-loaded and loaded reinforced concrete beams." Proc., 11th Int. Conf. on Alkali Aggregate Reaction, ICON/CANMET, 999-1008.

Multon, S., and Toutlemonde, F. (2006). "Effect of applied stresses on alkali-silica reaction-induced expansions." Cem. Concr. Res., 36(5), 912-920.

Nilsson, L. O. (1983). "Moisture effects on the alkali-silica reaction." Proc., Int. Conf. on Alkalis in Concrete, Danish Concrete Association, Brussels, Belgium.

Olafsson, H. (1986). "The effect of relative humidity and temperature on alkali expansion of mortar bars." Proc., 7th Int. Conf. on Alkali Aggregate Reaction in Concrete, Noyes Publications, Norwich, NY, 461-465.

Ono, K. (1990). "Strength and stiffness of alkali-silica reaction concrete and concrete members." Struct. Eng. Rev., 2, 121-125.

Pleau, R., Bérubé, M., Pigeon, M., Fournier, B., and Raphaël, S. (1989). "Mechanical behaviour of concrete affected by ASR." Proc., 8th Int. Conf. on Alkali-Aggregate Reaction, Society of Material Science, Elsevier, Amsterdam, Netherlands, 721-726.

Poyet, S., et al. (2006). "Influence of water on alkali-silica reaction: Experimental study and numerical simulations." J. Mater. Civ. Eng., 10.1061/(ASCE)0899-1561(2006)18:4(588), 588-596.

Salomon, M., and Panetier, J. (1994). "Quantification du degré d'avancement de l'alcali-réaction dans les bétons et la néofissuration associée." Proc., 3rd CANMET/ACI Int. Conf. on Durability of Concrete, ACI, 383-401.

Sibbick, R., and Page, C. (1992). "Susceptibility of various UK aggregates to alkali-aggregate reaction." Proc., 9th Int. Conf. on Alkali-Aggregate Reaction in Concrete, Vol. 2, Concrete Society, Slough, U.K., 980-987.

Siemes, T., and Visser, J. (2000). "Low tensile strength in older concrete structures with alkali-silica reaction." Proc., 11th Int. Conf. on Alkali Aggregate Reaction, ICON/CANMET, 1029-1038.

Swamy, R., and Al-Asali, M. (1986). "Influence of alkali-silica reaction on the engineering properties of concrete." Proc., Symp. on Alkalis in Concrete, ASTM, West Conshohocken, PA, 69-86.

Swamy, R., and Al-Asali, M. (1988). "Engineering properties of concrete affected by alkali-silica reaction." ACI Mater. J., 85(5), 367-374.

Swamy, R. N. (2002). The alkali-silica reaction in concrete, CRC Press, Boca Raton, FL.

Tomosawa, F., Tamura, K., and Abe, M. (1989). "Influence of water content of concrete on alkali-aggregate reaction." Proc., 8th Int. Conf. on Alkali Aggregate Reaction in Concrete, Elsevier, Amsterdam, Netherlands, 881-885.

Vivian, H. (1981). "The effect of drying on reactive aggregate and mortar expansions." Proc., 5th Int. Conf. on Alkali Aggregate Reaction in Concrete, National Building Research Institute, Cape Town, South Africa, 252-28. 